\title{
An ordered pathway of assembly of components required for polyadenylation site recognition and processing
}

\author{
Gregory M. Gilmartin and Joseph R. Nevins ${ }^{1}$
}

Howard Hughes Medical Institute, Department of Microbiology and Immunology, Duke University Medical Center, Durham, North Carolina 27710 USA

Four HeLa cell nuclear factors that are required for specific pre-mRNA cleavage and polyadenylation have been extensively purified, thereby permitting an investigation of the role of each in the 3 ' processing reaction. Two factors, termed PF1 and PF2, are required for specific polyadenylation of the cleaved RNA. PF1 is a poly(A) polymerase, and PF2 is a factor that confers AAUAAA specificity to the reaction. Both of these factors, along with two additional factors termed CF1 and CF2, are required for the endonucleolytic cleavage of the premRNA. The ability of each of these factors to form specific complexes with the pre-mRNA was assayed using native gel electrophoresis. Two distinct complexes were detected. PF2 forms an initial complex with the pre-RNA, dependent on the AAUAAA sequence element but independent of specific downstream sequences. Formation of the PF2-RNA complex permits the subsequent interaction of CF1 and the formation of a second, larger complex. CF1 binding requires the downstream sequence element in addition to PF2 binding. Whereas the PF2-RNA complex is unstable and dissociates rapidly, the ternary complex formed by CF1, PF2, and RNA is stable. Thus, the interaction of CF1, dependent on the downstream sequence element, can be viewed as a commitment of the poly(A) site for processing. On the addition of the poly(A) polymerase (PF1) and factor CF2, the pre-mRNA is specifically cleaved at the poly(A) site.

[Key Words: pre-mRNA cleavage; pre-mRNA polyadenylation; committed complex]

Received August 28, 1989; revised version accepted October 11, 1989.

The expression of a eukaryotic gene is a complex process involving not only RNA transcription but also the subsequent processing of the pre-mRNA into a mature, functional mRNA. A variety of studies have demonstrated that several RNA processing events, including the generation of the mRNA 3' terminus, contribute to the regulation of gene expression (Nevins 1983). The formation of the $3^{\prime}$ termini of polyadenylated mRNAs requires the specific endonucleolytic cleavage of the premRNA and the subsequent addition of $\sim 200$ adenylate residues. Probably the best example of a regulatory role for RNA 3' processing is the production of the immunoglobulin heavy chain mRNAs, whereby the differential expression of immunoglobulin $\mu$ mRNAs during B cell maturation appears to result in part from alternative poly(A) site selection (for review, see Guise et al. 1989).

The identification of the components of the 3 '-processing complex and an elucidation of the nature of their interaction with the pre-mRNA is crucial to the understanding of the role of this reaction in the regulation of gene expression. Specifically, it is likely that changes in poly(A) site usage are the result of changes in rate-lim-

${ }^{1}$ Corresponding author. iting factors that direct the processing event. The RNA recognition elements for such factors consist of two cisacting sequence elements that define the site and efficiency of cleavage and polyadenylation-a highly conserved AAUAAA hexamer 10-30 nucleotides upstream of the cleavage site (Proudfoot and Brownlee 1976; Fitzgerald and Shenk 1981; Montell et al. 1983) and an amorphous downstream U- or GU-rich element $/ \mathrm{Si}$ monsen and Levinson 1983; Gil and Proudfoot 1984; McDevitt et al. 1984; Sadofsky and Alwine 1984; Conway and Wickens 1985; McLauchlan et al. 1985) that possesses neither an identifiable consensus sequence nor a conserved secondary structure.

The development of in vitro systems that faithfully cleave and polyadenylate exogenously added pre-mRNA, dependent on the known cis-acting sequence elements, has been an important first step toward the elucidation of the mechanism of $3^{\prime}$ processing (Hart et al. 1985; Moore and Sharp 1985; Moore et al. 1986; Zarkower et al. 1986). These systems provide a functional assay for the identification of the factors involved in poly(A) site processing. Furthermore, the ability to analyze the cleavage and the polyadenylation events independently has also permitted the investigation of the individual re- 
quirements of each of these reactions (Moore et al. 1986). Multiple components have been shown to be required for both the cleavage and polyadenylation reactions (Christofori and Keller 1988; Gilmartin et al. 1988; McDevitt et al. 1988; Takagaki et al. 1988). A poly(A) polymerase has been partially purified which, although devoid of specificity in the presence of $\mathrm{Mn}^{2+}$, functions in an AAUAAA-dependent manner in the presence of $\mathrm{Mg}^{2+}$ and a complementing extract fraction (McDevitt et al. 1988; Takagaki et al. 1988; Christofori and Keller 1989). This poly(A) polymerase-containing fraction has been shown to be required for both the polyadenylation and cleavage reactions (Christofori and Keller 1989). Although initial studies using both extracts and crude fractions revealed a sensitivity of the cleavage reaction to both micrococcal nuclease and $\alpha$-Sm sera (Gilmartin et al. 1988), and biochemical fractionation has provided evidence that U11 snRNP cofractionates with the processing activity (Christofori and Keller 1988), there is, nevertheless, no conclusive evidence as yet for the involvement of a specific snRNP in the $3^{\prime}$ processing reaction.

The development of an in vitro system has also permitted the investigation of the formation of RNA $3^{\prime}$-processing complexes. By incubating suitable RNAs with crude nuclear extracts, specific complexes have been detected whose formation correlates with poly(A) site processing. The formation of pre-cleavage complexes has been shown to depend on the AAUAAA hexamer and the downstream element. Both of these sequences have been shown to be specifically protected from RNase T1 and RNase $\mathrm{H}$ digestion (Humphrey et al. 1987; SkolnikDavid et al. 1987; Zarkower and Wickens 1987a; Stefano and Adams 1988). Pre-cleaved RNAs (RNAs lacking the downstream sequence) also form complexes with the consequent RNase protection of the AAUAAA hexamer (Zarkower and Wickens 1987a). Chemical modifications of the RNA substrate or hybridization of oligonucleotides to the AAUAAA that block $3^{\prime}$-processing were also shown to disrupt specific complex formation (Conway and Wickens 1987; Zarkower and Wickens 1987b). Finally, UV cross-linking has been used to examine the interaction of proteins present in crude extracts with the pre-mRNA. Proteins of $64-68 \mathrm{kD}$ and $155 \mathrm{kD}$ have been cross-linked to RNA in an AAUAAA-dependent manner and have been detected in pre-cleavage complexes (Moore et al. 1988; Wilusz and Shenk 1988).

Despite these considerable advances in identifying interactions between nuclear factors and poly(A) site sequences, the relationship of these factors to the functional activities identified by biochemical fractionation and their role in the processing reaction has yet to be determined. In this report we present the extensive purification of several components of the $3^{\prime}$ processing complex. This has allowed the subsequent analysis of the role these factors play in the recognition and processing of the pre-mRNA. Through an analysis of the interaction of these factors with RNA substrates, we describe an ordered pathway of association of factors with premRNA.

\section{Results \\ Specific polyadenylation of a pre-cleaved RNA requires a poly $(A)$ polymerase and a specificity factor}

The production of mRNA 3 ' ends entails two reactions that can be independently assayed in vitro (Moore and Sharp 1985; Moore et al. 1986). The first reaction, dependent on both the AAUAAA hexamer and the GU-rich downstream element, involves the specific endonucleolytic cleavage of the pre-mRNA. The subsequent polyadenylation step adds $\sim 200$ adenylate residues to the $3^{\prime}$ end of the cleaved pre-mRNA in an AAUAAA-dependent reaction. Our initial fractionation studies, as well as those of others, demonstrated that multiple components were involved in both the cleavage and polyadenylation reactions (Christofori and Keller 1988; Gilmartin et al. 1988; McDevitt et al. 1988; Takagaki et al. 1988). To identify these factors and determine their roles in mRNA 3' processing, we have pursued the further biochemical fractionation of nuclear extracts. Initially, we focused on the polyadenylation reaction, which had been shown to require at least two components, here termed PF1 and PF2, that are separated at the first step of fractionation of nuclear extracts on a DEAE-Sepharose column (McDevitt et al. 1988).

The DE150 fraction contained PF1 activity that cofractionated upon subsequent purification with a nonspecific poly(A) polymerase activity. We have purified this component further using an assay for the specific polyadenylation of a 'pre-cleaved' adenovirus L3 premRNA (see Experimental procedures). The fractionation scheme for the purification of PF1 is illustrated in Figure 1. The initial PF1 fractions were assayed in the presence of the complementing factor PF2, present in the DE250 fraction. Subsequent fractionations of PF1 and PF2 were carried out in parallel such that the assays at each succeeding step used progressively more purified forms of both components. The final step in the purification of PF1 was a $10-30 \%$ glycerol gradient in which the activity sedimented with an apparent native molecular weight of $40-50 \mathrm{kD}$ (Fig. 2A). Analysis of these fractions by SDS gel electrophoresis revealed proteins of 56,39 , and $31 \mathrm{kD}$ in the active fractions (Fig. 2B). However, a careful examination of the fractions suggests that only the $39-\mathrm{kD}$ polypeptide (indicated by the arrow) cosedimented with PF1 activity.

The fractionation scheme for factor PF2 is also depicted in Figure 1. The final step in the purification was a glycerol gradient in which the activity sedimented with an apparent native molecular weight of $\sim 250 \mathrm{kD}$ (Fig. 3A). Analysis of these fractions by SDS gel electrophoresis exhibited a considerably more complex pattern than had been observed for PF1 (Fig. 3B), making it difficult to correlate PF2 activity with a particular polypeptide(s), although a careful inspection of the pattern in comparison to the PF2 activity profile indicated that several polypeptides cosedimented with PF2 activity. As an alternative approach, UV cross-linking was used to examine the ability of any of these proteins, as well as those present in the PF1 fraction, to interact specifically 


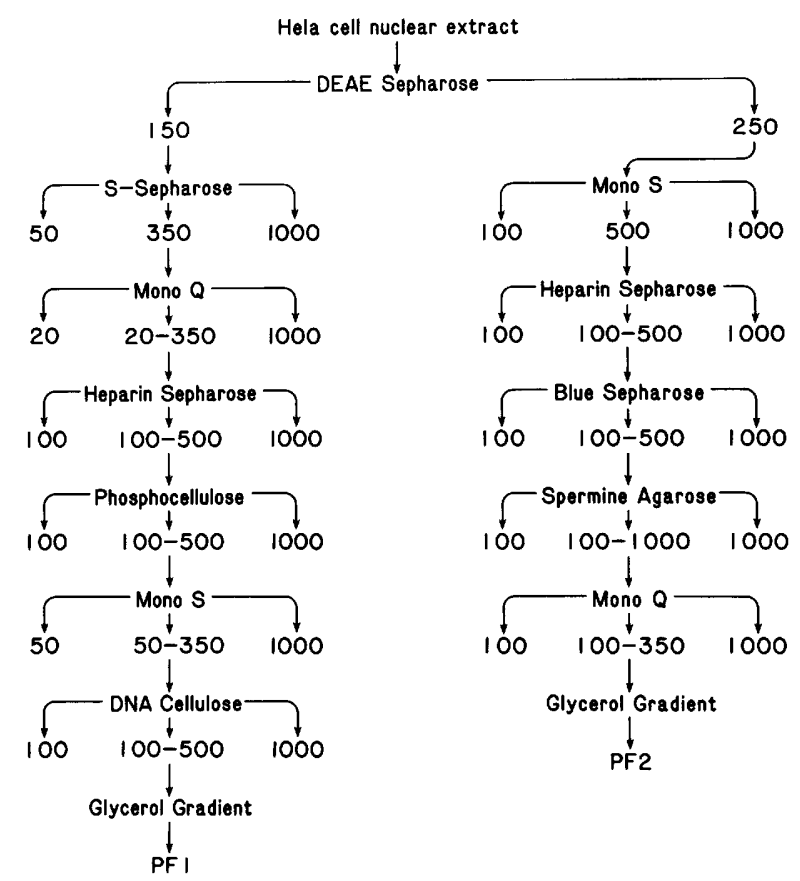

Figure 1. Polyadenylation factor fractionation scheme. Flowchart illustrating the sequence of chromatographic and centrifugation steps used for the purification of the polyadenylation factors PF1 and PF2. Numbers indicate salt concentrations (mM) for column loading and elution.

with the RNA substrate. The peak DNA-cellulose PF1 and Mono Q PF2 fractions were incubated in the presence of $\left[\alpha-{ }^{32} \mathrm{P}\right] \mathrm{GTP}$-labeled pre-cleaved RNA substrate containing either an intact AAUAAA or the hexamer point mutation AACAAA. After a brief incubation at $30^{\circ} \mathrm{C}$ to allow for complex formation, the reactions were irradiated with 254-nm wavelength light at $0^{\circ} \mathrm{C}$. The reactions were subsequently digested with RNase A and subjected to SDS gel electrophoresis, followed by autoradiography. Because the sequence encompassing the hexamer is UUCAAUAAAGGC, proteins binding at this site may be expected to be covalently coupled to a ${ }^{32} \mathrm{P}$ containing oligonucleotide following RNase A digestion. Figure $3 \mathrm{C}$ shows that although no protein in the PF1 fraction was labeled on UV irradiation, several proteins in the PF2 fraction were labeled after UV crosslinking. Of these, only a protein of $170 \mathrm{kD}$ and one of $130 \mathrm{kD}$ were labeled specifically by the AAUAAA-containing RNA. A prominent protein of $\sim 65 \mathrm{kD}$ was labeled by both RNAs, with little specificity for the AAUAAA. The coincubation of PF1 and PF2 showed no additional protein cross-linking. Because the PF2 factor appears to mediate recognition of the AAUAAA element, as shown in several experiments described below, we conclude that the 170 - and $130-\mathrm{kD}$ polypeptides may indeed be components of the PF2 activity.

As illustrated in Figure 4, PF2 failed to elongate a variety of RNA substrates in the presence of $\mathrm{Mg}^{2+}$ (lanes $9-12$ ). There was also no evidence for activity in the presence of $\mathrm{Mn}^{2+}$, which has been shown to relax the specificity of a number of polymerases (Kornberg 1980).
In contrast, $\mathrm{PF} 1$ polyadenylated each of the RNAs in the presence of $\mathrm{Mn}^{2+}$ (lanes 5-8) but not $\mathrm{Mg}^{2+}$ (lanes 1-4). Mixing PF1 and PF2 in the presence of $\mathrm{Mg}^{2+}$ resulted in specific polyadenylation, as the pre-cleaved RNA containing the AAUAAA was polyadenylated (lane 17) and the point mutant (AACAAA) was not (lane 18). As had been observed in crude extracts (Sheets and Wickens 1989), cleaved RNAs containing a short poly(A) tail of 40 adenylate residues were further polyadenylated by the purified fractions in an AAUAAA-independent reaction (lanes 19 and 20). The poly(A) polymerase alone was not sufficient, however, for the elongation of the poly $(\mathrm{A})$ tail (lane 3). Incubation of both components in the presence of $\mathrm{Mn}^{2+}$ exhibited no specificity of polyadenylation (lanes 21-24). These results therefore support the following conclusions: PF1 possesses poly(A) polymerase activity that cofractionates with a single polypeptide of $\sim 39 \mathrm{kD}$; PF2 is apparently a complex of multiple proteins, some of which may interact directly with the AAUAAA element; the PF2 complex alone has no polymerase activity, but it does impart specificity to the poly(A) polymerase in the form of AAUAAA recognition.

\section{The polyadenylation factors PF1 and PF2 and two additional factors are required for cleavage}

Although the initial DEAE fractions (Fig. 5) alone are devoid of cleavage activity, the activity can be reconstituted by mixing the DE150 and DE250 fractions (Gilmartin et al. 1988). PF1, purified from the DE150 fraction, can, in fact, reconstitute cleavage when mixed with the DE250 fraction (Fig. 6A, lane 4). Thus, PF1 is required for cleavage as well as for polyadenylation. Likewise, PF2 can complement the DE 150 fraction so as to restore cleavage activity (Fig. 6B, lane 3). However, mixing PF1 and PF2 does not reconstitute cleavage activity (Fig. 6C, lane 7), thus indicating that although they are required for cleavage, they are not sufficient. Fractionation of the DE150 material, as detailed in Figure 5, yielded two fractions, CF1 and CF2, which are required along with PF2 to reconstitute cleavage activity (Fig. 6C, lane 13). The authenticity of the cleavage activity is confirmed by its dependence on an intact AAUAAA sequence (Fig. 6C, lane 14). The CF2 fraction also contains PFl activity (data not shown); however, because purified PF1 is unable to complement PF2 and $\mathrm{CF} 1$ for cleavage (Fig. 6C, lane 15), this indicates a requirement for a cleavage-specific activity in the CF2 fraction. As yet, we have been unable to isolate the CF2 cleavage activity from PF1; thus, the CF2 activity remains relatively crude at this time. It should be noted that CF1 and CF2 are also present in the DE250 fraction, but their purification from this material has been hampered by low levels of PF2 contamination. The CF1 activity has been purified further, as detailed in Figure 5 . The CF1 activity sediments with an apparent native molecular weight of $\sim 170 \mathrm{kD}$ in a $5-30 \%$ glycerol gradient, and SDS gel analysis of the peak fractions reveals polypeptides of 76,62 , and $46 \mathrm{kD}$ that cosediment with activity (data not shown). 

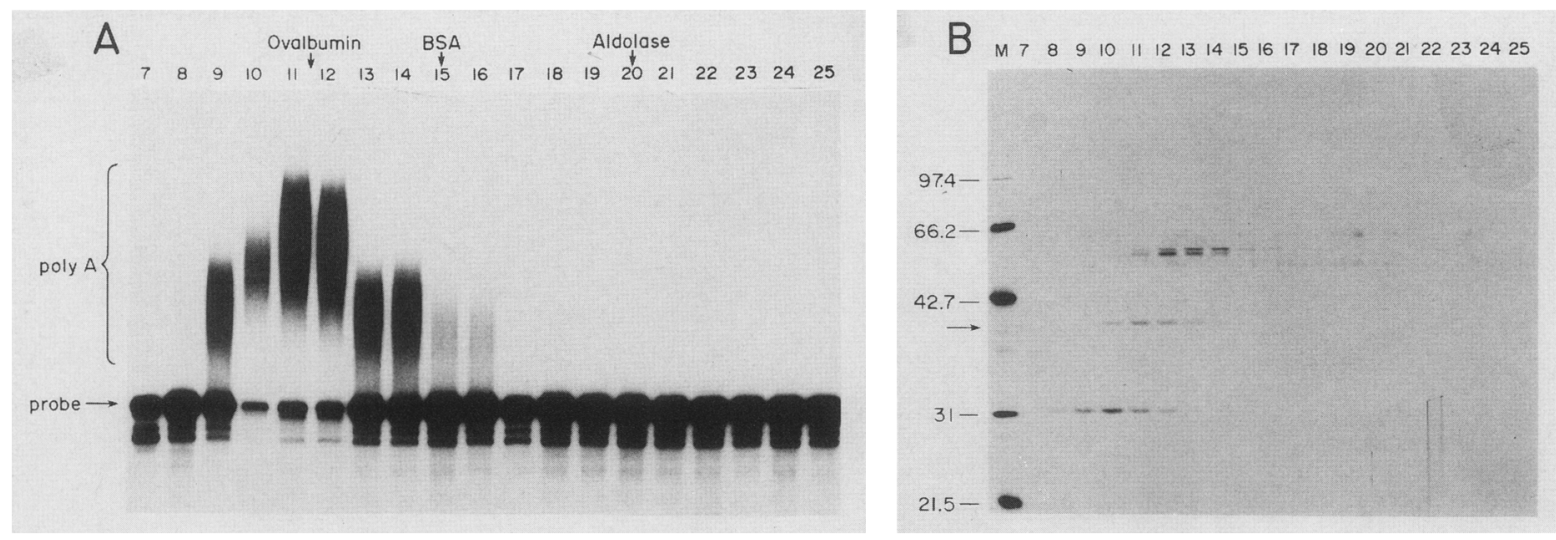

Figure 2. Analysis of polyadenylation factor PF1. (A) Glycerol gradient sedimentation. DNA-cellulose fractions containing PF1 activity were pooled and sedimented in a $10-30 \%$ glycerol gradient, as described in Experimental procedures. The pre-cleaved RNA substrate was incubated in the presence of the glycerol gradient fractions and a Mono Q PF2 fraction (Fig. 1). Fractions are numbered from the top to the bottom of the glycerol gradient and are given at top. The positions of the protein markers run in a parallel gradient are indicated. $(B)$ SDS-PAGE of glycerol gradient fractions. Aliquots of the glycerol gradient fractions assayed in $A$ were electrophoresed on a $10 \%$ SDS-polyacrylamide gel, followed by silver staining. Positions of the protein standards are indicated. The arrow indicates the position of the $39-\mathrm{kD}$ protein that comigrates most closely with PF1 activity. The fractions are numbered as in $A$.

\section{The PF2 factor specifically recognizes the AAUAAA} hexamer

We explored the ability of the purified factors to form a specific complex with the pre-mRNA. Assays using factors PF1 and PF2 with various RNA substrates are shown in Figure 7A. Factors were incubated with the RNA under standard processing conditions, followed by the addition of heparin, and the mixture was analyzed on a nondenaturing polyacrylamide gel. Incubation of PF1 revealed no complex formation with any of the probes (Fig. 7A, lanes 1-4). The bands present in each of these lanes are also present in the absence of protein (data not shown). However, incubation of PF2 with the various probes generated a specific complex (labeled A), dependent on the AAUAAA sequence but independent
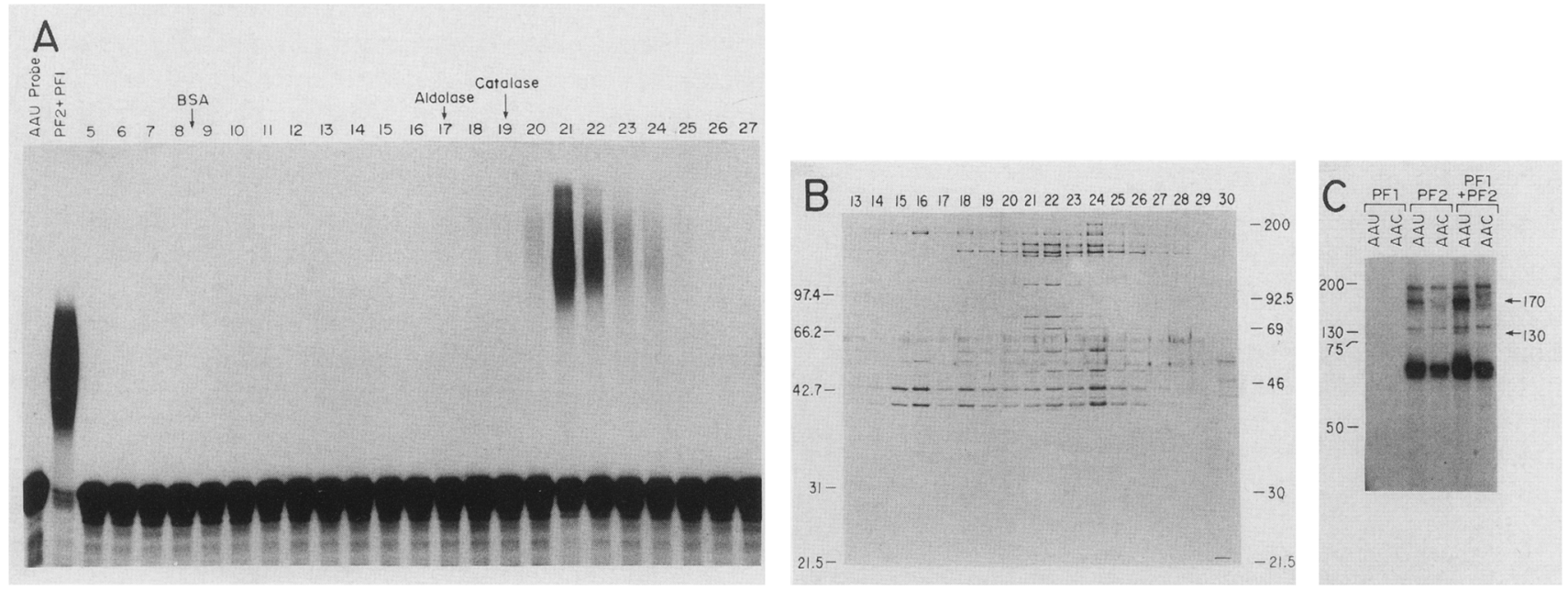

Figure 3. Analysis of polyadenylation factor PF2. (A) Glycerol gradient sedimentation. Mono Q fractions containing PF2 activity (Fig. 1) were centrifuged in a $15-40 \%$ glycerol gradient, as described in Experimental procedures. The pre-cleaved RNA substrate was incubated in the presence of the glycerol gradient fractions and a DNA-cellulose PF1 fraction (Fig. 1). Fractions are numbered from the top to the bottom of the glycerol gradient and are given at top. The activity of the input Mono Q fraction is shown in lane 2. The positions of the protein markers run in a parallel gradient are indicated. $(B)$ SDS-PAGE of glycerol gradient fractions. Aliquots of the glycerol gradient fractions assayed in $A$ were electrophoresed on a $10 \%$ SDS-polyacrylamide gel, followed by silver staining. Molecular weight markers are indicated. The fractions are numbered as in $A$. $(C)$ UV cross-linking of PF1 and PF2 activities to wild-type (AAUAAA) and mutant (AACAAA) pre-cleaved RNAs. DNA-cellulose PF1 and Mono Q PF2 fractions (Fig. 1) were incubated under polyadenylation conditions, irradiated with UV light, and electrophoresed on a 10\% SDS-polyacrylamide gel, as described in Experimental procedures. The positions of wild-type-specific proteins of 130 and $170 \mathrm{kD}$ are denoted by arrows. Molecular weight markers are indicated. 
Figure 4. Specificity of action of polyadenylation factors. DNA-cellulose PFl and Mono Q PF2 fractions (Fig. 1) were assayed separately (lanes $1-16$ ) or in combination (lanes 17-24) in the presence of $\mathrm{Mg}^{2+}$ or $\mathrm{Mn}^{2+}$. The RNA substrate used is indicated above each lane: (AAU) pre-cleaved wild-type RNA containing an AAUAAA; (AAC) pre-cleaved mutant (AACAAA) RNA; [AAU + $\left.(\mathrm{A})_{40}\right]$ precleaved wild-type RNA with a $3^{\prime}$ addition of 40 adenylate residues; $\left[\mathrm{AAC}+(\mathrm{A})_{40}\right]$ precleaved mutant RNA with a 3 ' addition of 40 adenylate residues. The probes alone were run in lanes 25-28.

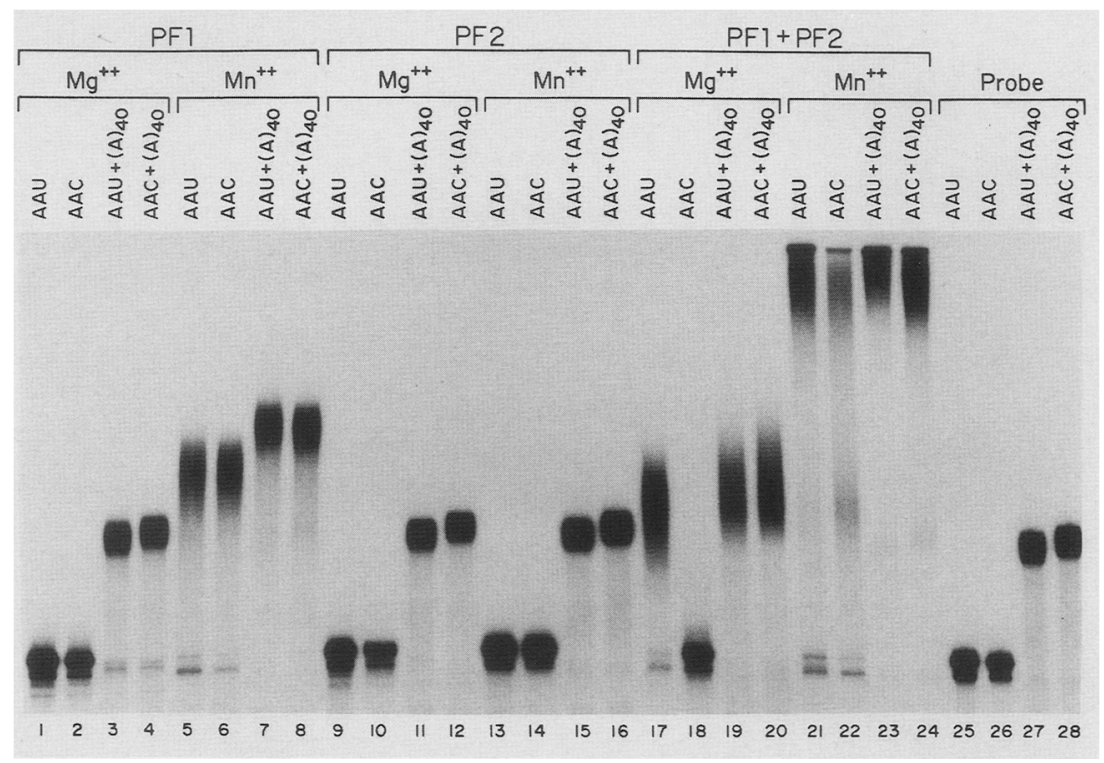

of the downstream element (Fig. 7A, lanes 5-8). The RNA containing the downstream sequence did appear to be more efficient in forming the complex, but this appears to be a nonspecific effect, unrelated to the nature of the downstream sequence (see Fig. 8). We suspect that the complex is simply more stable on a substrate with a $3^{\prime}$ extension. Addition of PF1, along with PF2, did not detectably alter the PF2-specific complex (Fig. 7A, lanes 9-12). Therefore, we conclude that PF2 possesses the ability to recognize the AAUAAA sequence element and to thereby interact with the RNA substrate. PF1 appar-

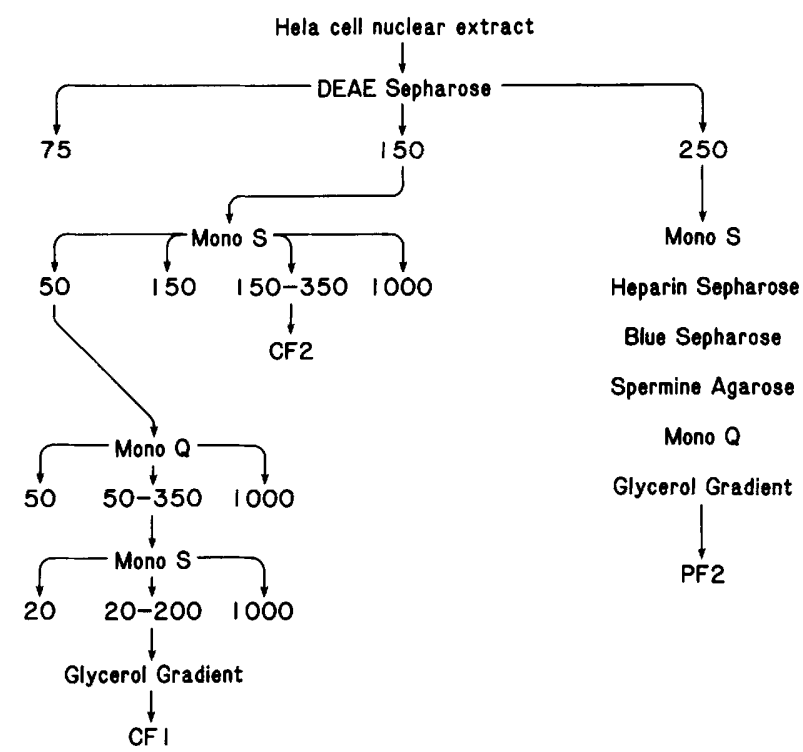

Figure 5. Cleavage-factor fractionation scheme. Flowchart illustrating the sequence of chromatographic and centrifugation steps used for the purification of the cleavage activities CF1, CF2, and PF2. The numbers indicate the salt concentrations for column loading and elution. The fractionation of factor PF2 is the same as that presented in Fig. 1. ently does not contribute to this complex. This is consistent with the presence of proteins in the PF2 fraction, which can be specifically cross-linked to an AAUAAAcontaining RNA (shown in Fig. 3C).

The interaction of CF1 with the pre-mRNA requires both PF2 and the downstream sequence element

Endonucleolytic cleavage at the poly(A) site requires both the AAUAAA hexamer, as well as the GU-rich downstream sequence (for review, see Birnstiel et al. 1985). The ability of PF2 to recognize the AAUAAA in the absence of the downstream element suggests that a second factor may be responsible for the recognition of the downstream element. This is consistent with the observation that a larger complex was formed on a substrate containing both the AAUAAA and the downstream element than on a substrate containing the hexamer alone (Zarkower and Wickens 1987b). Each of the fractions required for poly(A) site cleavage was therefore assayed for the ability to form a complex with an RNA containing both the AAUAAA hexamer and downstream sequences. In contrast to the ability of PF2 to form a specific complex, neither CF1 nor CF2 was able to generate a detectable complex (Fig. 7B). However, mixing of PF2 and CF1 resulted in the formation of a complex (denoted B) that migrated slower than the PF2 A complex and that was dependent on the AAUAAA element. Interestingly, CF2 appeared to have a destabilizing effect, because the addition of CF2, along with PF2, disrupted the formation of the PF2-RNA complex (complex A) (Fig. 7B, lane 9). Although CF2 also reduced the B complex resulting from PF2 and CF1 interaction, this mixture represents complete processing conditions and we suspect that the reduction in complex B is a reflection of processing.

The sequence requirement for CFl interaction was investigated further. RNA substrates containing an intact 


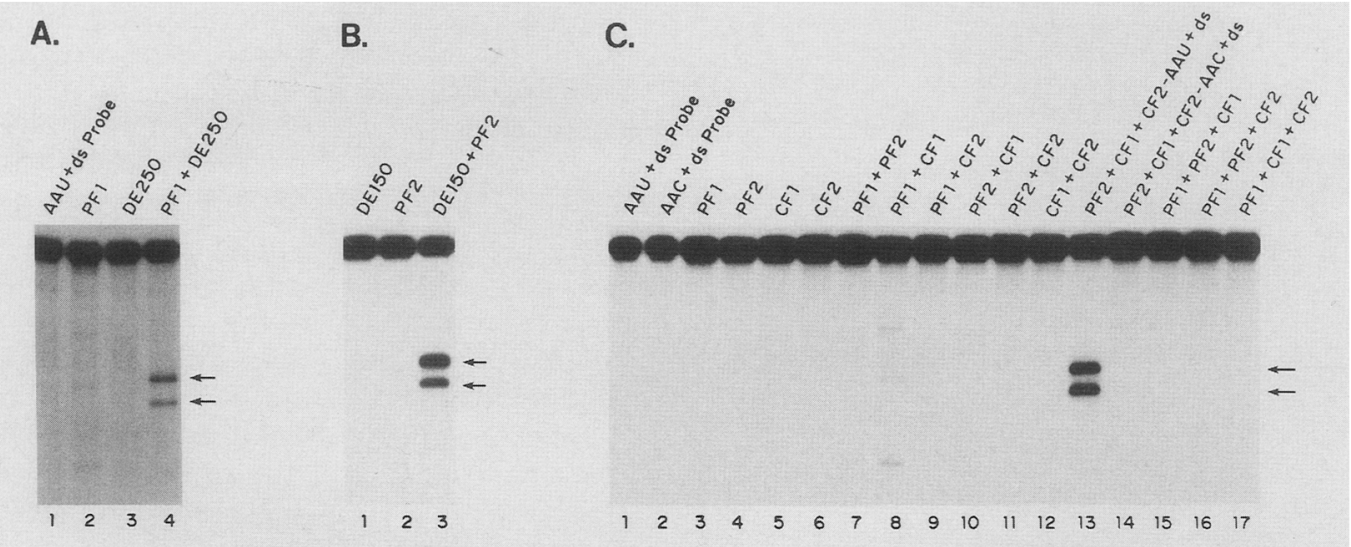

Figure 6. Analysis of the requirement for PF1 and PF2 in the reconstitution of the $3^{\prime}$ cleavage reaction. $(A)$ Purified PF1 (DNA-cellulose fraction) and a DE250 fraction (Fig. 1) were assayed for cleavage activity, either separately or in combination. Arrows indicate positions of the expected 5' products of cleavage of the L3 RNA (AAU + ds). (B) Purified PF2 (Mono Q fraction) and a DE150 fraction (Fig. 1) were assayed for cleavage activity, either separately or in combination. (C) DNA-cellulose PF1 and Mono Q PF2 (Fig. 1), and the Mono S cleavage factors CF1 and CF2 (Fig. 5) were assayed for cleavage activity, either separately or in combination. All reactions used the wild-type RNA substrate (AAU + ds) containing both the AAUAAA and the downstream element, with the exception of the reaction in lane 14 , in which a mutant (AACAAA) RNA (AAC+ds) was used.

downstream sequence were compared with an RNA containing plasmid sequence in place of the specific L3 downstream sequence. Incubation of each of the AAUAAA-containing RNAs in the presence of PF2 alone resulted in the formation of the A complex (Fig. 8), thus demonstrating that the PF2 interaction was AAUAAA-dependent but independent of the specific downstream sequence. Addition of both PF2 and CF1
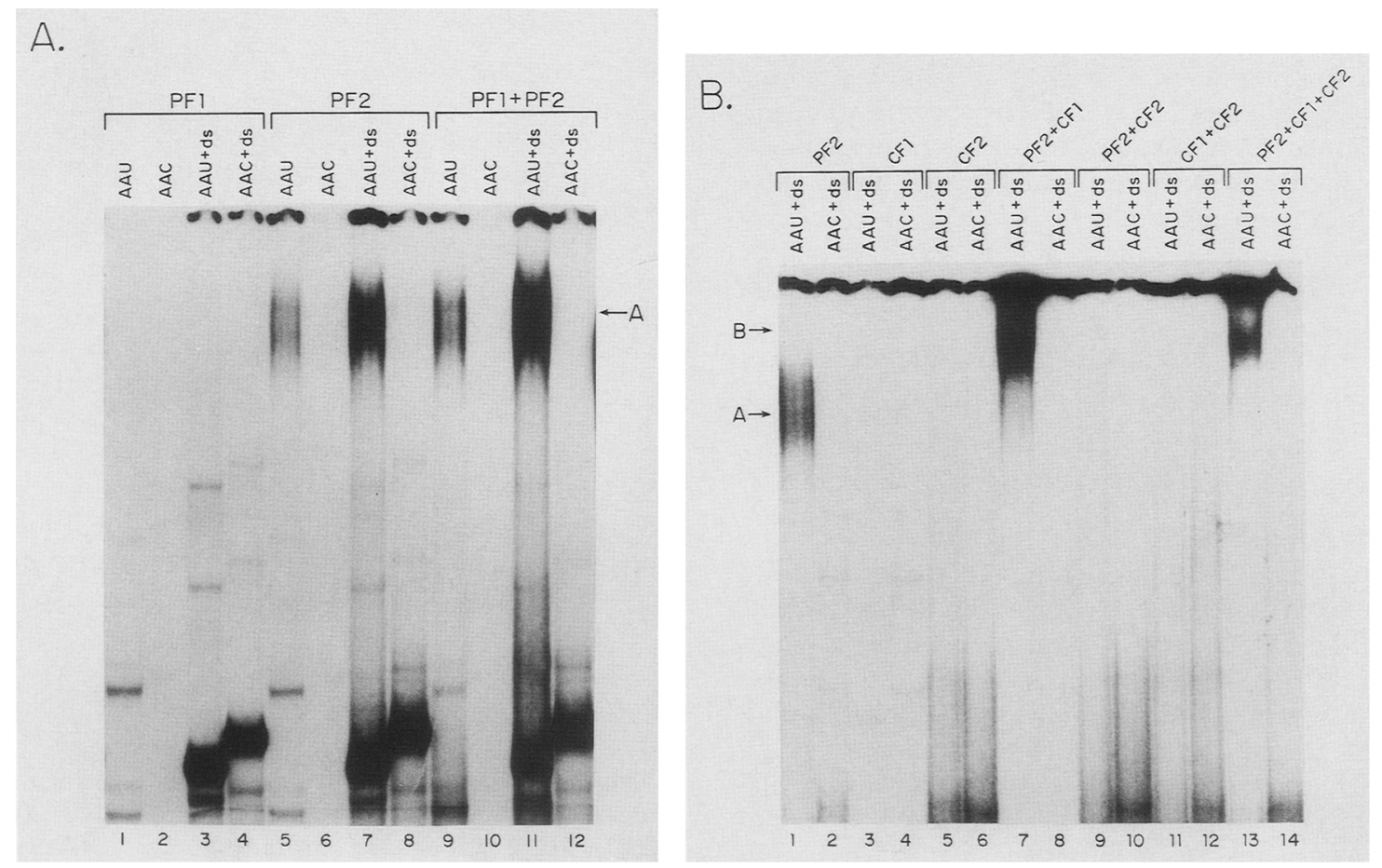

Figure 7. RNA-protein complex formation with polyadenylation and cleavage factors. (A) DNA-cellulose PF1 and Mono Q PF2 fractions (Fig. 1) were assayed separately or in combination, using the L3 RNAs for specific complex formation by RNA gel retardation as described in Experimental procedures. Fractions were incubated with wild-type RNA containing (AAU + ds) or lacking (AAU) the downstream sequence, or with a mutant (AACAAA) RNA containing (AAC + ds) or lacking (AAC) the downstream sequence. (B) Mono S CF2, Mono Q PF2, and Mono S CF1 fractions (Fig. 5) were assayed separately or in combination for specific complex formation by RNA gel retardation, as described in Experimental procedures. Fractions were incubated with either wild-type (AAU + ds) or mutant $(A A C+d s)$ RNAs containing the downstream sequence. 


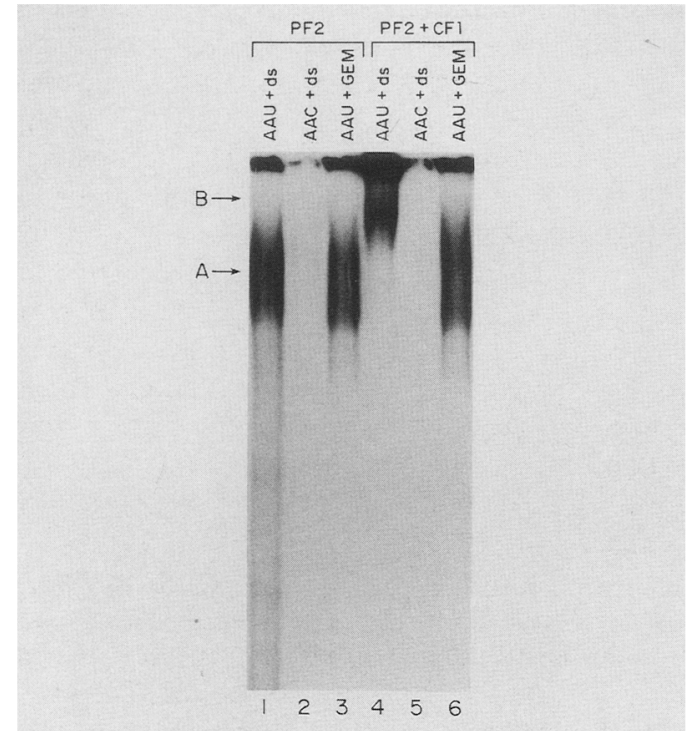

Figure 8. Downstream sequence requirements for complex formation. Mono Q PF2 and Mono S CF1 fractions (Fig. 5) were assayed for specific complex formation by RNA gel retardation. Fractions were incubated with RNAs containing the wild-type AAUAAA hexamer with an intact downstream sequence $(A A U+d s)$ or with a replacement of the downstream sequence by vector sequences (AAU + GEM). Fractions were also incubated with an RNA containing the mutant AACAAA hexamer with an intact downstream sequence $(A A C+d s)$.

generated complex B but only with an RNA containing the AAUAAA element, as well as the specific L3 downstream element. Replacement of the specific L3 downstream sequence by vector sequence, which inactivates the in vitro processing of the RNA, resulted in the formation of A complexes comparable to those formed by PF2 alone. Therefore, these results demonstrate that CF1 binding not only requires the PF2-RNA complex, which is AAUAAA-dependent, but also the presence of the specific downstream sequence element.

\section{Stable complex formation by PF2 and CF1}

Because of the limited sequence requirements for the formation of the PF2-RNA A complex, we investigated the possibility that the subsequent interaction of CF1 results in the formation of a stable or 'committed' complex. The relative stability of the A and B complexes was therefore assayed by addition of cold RNA substrate following the initial formation of the complexes. As depicted in Figure 9, the PF2-RNA A complex readily dissociated so that $10 \mathrm{~min}$ after the addition of a 50 -fold molar excess of cold RNA substrate, there was virtually no A complex remaining. In sharp contrast, there was no detectable dissociation of the PF2-CF1-RNA B complex after $10 \mathrm{~min}$ in the presence of the RNA competitor. Therefore, we conclude that the initial interaction of PF2 with the RNA, involving a recognition of the AAUAAA element, results in the formation of a relatively unstable complex that likely only exists very transiently. The subsequent interaction of CF1 with the PF2-RNA complex, by virtue of recognition of the downstream element, results in the formation of a stable ternary complex.

\section{Discussion}

A series of reports over the past several years demonstrated that the 3 ' processing of polyadenylated mRNAs requires the participation of multiple components (Christofori and Keller 1988; Gilmartin et al. 1988; McDevitt et al. 1988; Takagaki et al. 1988). Clearly, a final understanding of the mechanism of this critical RNA processing event will require the identification of the cis-acting RNA sequences directing the processing, identification of the nuclear factors that mediate the processing reaction, and the elucidation of the function of each of these factors. Only then will it be possible to begin to address the mechanisms whereby poly(A) site function is regulated. A variety of experiments have succeeded in accomplishing the first task of identifying the pre-mRNA sequences that are required for 3 ' processing (for review, see Birnstiel et al. 1985). It is clear that the highly conserved AAUAAA sequence and the less conserved GU-rich downstream sequence are both important for processing. More recently, progress has been re-

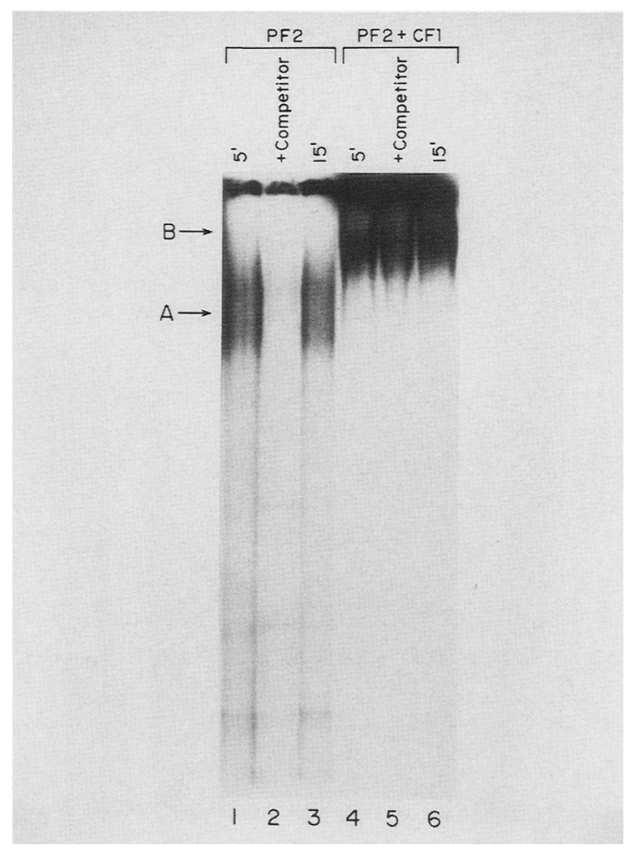

Figure 9. Stability of RNA-protein complex formation. Complexes formed on the wild-type RNA substrate (AAU +ds) in the presence of Mono Q PF2 and Mono S CF1 fractions (Fig. 5) were assayed for stability upon challenge with homologous RNA competitor, as described in Experimental procedures. (Lanes 1 and 4) Complexes formed after 5 min; (lanes 2 and 5) competition-resistant complexes (after initial complex formation for 5 min a 50-fold excess of cold AAU + ds RNA was added and the reaction was incubated for an additional $10 \mathrm{~min}$; (lanes 3 and 6) complexes formed at $15 \mathrm{~min}$ in the absence of RNA competitor. 
ported in identifying the factors involved in the $3^{\prime}$ processing of pre-mRNA (for review, see Humphrey and Proudfoot 1988). At least four factors are required for mRNA $3^{\prime}$ processing. All four factors are required for cleavage of the pre-mRNA, whereas two are sufficient for the poly(A) addition reaction. In this report we describe results that begin to define the role of these factors in the processing event so that we can now begin to address the basis for changes in factor activity or composition in response to regulatory events.

\section{Polyadenylation factors}

Almost certainly, $\mathrm{PF} 1$ is the actual poly(A) polymerase that elongates the $3^{\prime}$ end of the mRNA with a poly(A) tail. In the absence of other factors, PF1 is capable of poly(A) addition but without specificity. The PF2 factor appears to impart specificity to the polyadenylation reaction through the recognition of the AAUAAA hexamer. The requirement for PF2 in both the cleavage and polyadenylation reactions is consistent with its role in AAUAAA recognition. In addition, Zarkower and Wickens (1987a) have shown that a pre-cleaved RNA containing the AAUAAA sequence competes effectively for the formation of the pre-cleavage complex, supporting the role of a common AAUAAA recognition factor in both the cleavage and polyadenylation reactions.

In contrast to the PF1 activity, which appears to be a single polypeptide of $39 \mathrm{kD}$, the PF2 fraction appears to be more complex. The PF2 activity sediments at a rate that suggests a native molecular weight of $\sim 250 \mathrm{kD}$. Proteins of 130 and $170 \mathrm{kD}$ present in the purified PF2 fractions were found to be specifically UV cross-linked to the RNA substrate dependent on the AAUAAA. Whether these are the only components of the PF2 activity is not yet clear. An immediate consideration with respect to the composition of the PF2 activity is the possibility that this may be a small nuclear ribonucleoprotein (snRNP), particularly in light of previous experiments demonstrating a coprecipitation of AAUAAAcontaining oligonucleotides with $\alpha$-Sm antibody (Hashimoto and Steitz 1986). Furthermore, the PF2 factor is most likely a component of the CPF fraction described by Christofori and Keller (1988). Both PF2 and CPF give specificity to the polyadenylation reaction, both are required for cleavage and polyadenylation, and both activities possess a native molecular weight in the 200- to $300-\mathrm{kD}$ range. However, we have been unable to detect the cofractionation of any snRNA or Sm proteins with PF2. Although a very low level of an RNA corresponding in size to U11 could be detected in the most purified fraction by $\mathrm{pCp}$ labeling, it did not cofractionate with PF2 activity on either the Mono Q column or the glycerol gradient (data not shown).

\section{Cleavage factors}

The cleavage factor CF1 appears to be responsible for the specific recognition of the downstream element and in the context of PF2 and the AAUAAA hexamer sequence, forms a stable ternary complex. Subsequent addition of the CF2 fraction results in the endonucleolytic cleavage of the pre-mRNA. We suggest that the CF2 factor may possess the actual endonuclease responsible for cleavage, although it may also serve to potentiate the endonucleolytic activity of another component of the processing complex. The CF2 fraction also has the intriguing property of promoting the dissociation of the PF2-RNA complex in the absence of CF1. Such an activity may be required for the proofreading of the initial PF2-RNA complex and/or the dissociation of the postcleavage complex.

Finally, our previous studies demonstrated an activity in crude fractions, required for cleavage but not polyadenylation, which was sensitive to micrococcal nuclease (Gilmartin et al. 1988). Unfortunately, similar assays of the purified fractions have been hampered by the sensitivity of the factors to the control incubation of micrococcal nuclease in the presence of EGTA. Thus, whether there is a factor that is sensitive to micrococcal nuclease or whether this sensitivity was an anomaly of the crude fractions initially utilized is not yet clear. The role of an snRNP in the $3^{\prime}$ cleavage process will most likely be determined by more extensive purification of the individual components.

\section{A pathway for assembly of a processing complex}

The information gained thus far concerning the complexity of activities and the analysis of the formation of specific complexes using the partially purified processing factors has led us to propose an ordered pathway of complex assembly, as depicted in Figure 10. We suggest that the first step in assembly involves the interaction of PF2 with the pre-mRNA by virtue of its recognition of the AAUAAA hexamer. However, the PF2-RNA complex is relatively unstable, as evidenced by its rapid dissociation after addition of excess RNA substrate; we thus presume that this complex would exist only transiently in the cell. In a second step, CF1 recognizes the downstream element in the context of the PF2RNA interaction and forms a stable ternary complex with PF2 and the pre-mRNA. The independent binding of CF1 to the pre-mRNA has not been detected, and we thus presume that $\mathrm{CF} 1$ recognition requires the prior interaction of PF2. Once the stable ternary complex is formed, cleavage and polyadenylation occur in the presence of both CF2 and PF1. Although the simplest model would depict CF2 as the endonuclease, we have no evidence for such. Subsequent polyadenylation of the cleaved RNA requires only the AAUAAA recognition factor PF2 and the poly(A) polymerase (PF1), in the presence of $\mathrm{Mg}^{2+}$ and ATP.

The nature of these interactions should also be viewed in the context of the RNA sequence elements. It has long been noted that the highly conserved AAUAAA hexamer element is not sufficient to define a functional poly(A) site, because there are many examples of such sequences in the middle of transcription units. Only 


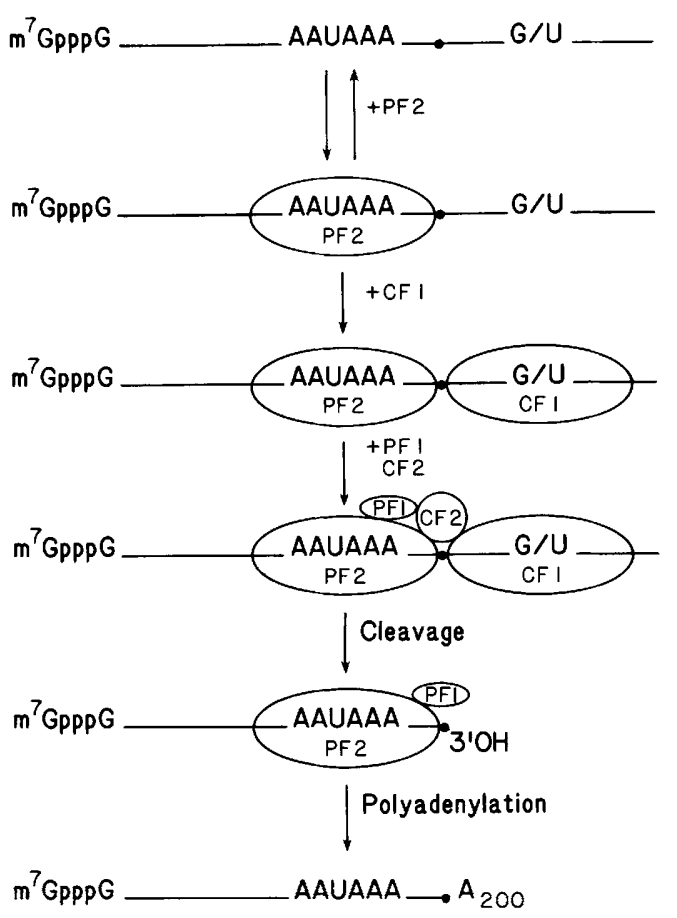

Figure 10. A schematic model of the ordered assembly of components required for pre-mRNA $3^{\prime}$ processing.

when the AAUAAA is paired with a GU- or U-rich downstream element is a functional poly $(\mathrm{A})$ site created (for review, see Birnstiel et al. 1985). Thus, one could speculate that the stabilities of the PF2 and PF2-CF1 interactions reflect the process of locating and defining a functional poly(A) site. That is, although PF2 may interact with an AAUAAA sequence in the middle of nascent RNA transcripts, this interaction rapidly dissociates in the absence of CFl binding at an adjacent site downstream. In essence, the poly(A) site is not 'committed' unless CF1 recognizes the downstream element and interacts with the RNA to form a stable complex. Although we have no direct evidence, we suspect that the stability of the RNA-PF2-CF1 complex results from a direct physical interaction between the PF2 and CF1 factors. This suggestion stems from the observation that the distance between the AAUAAA element and the downstream element is conserved among a variety of poly(A) sites. More compelling, however, is the observation that alterations of this spacing have a dramatic negative impact on the efficiency of poly(A) site utilization (McDevitt et al. 1986; Gil and Proudfoot 1987).

Selective poly(A) site utilization and regulation of poly(A) site function can also be envisioned in the framework of the above discussion. For instance, recent experiments have suggested that the poly(A) site in the late polyoma virus transcription unit is weak and not efficiently recognized, whereas addition of a $\beta$-globin poly(A) site results in very efficient polyadenylation (Lanoix et al. 1988). Furthermore, arguments have been put forward suggesting that differential use of the immunoglobulin $\mu_{\mathrm{s}}$ and $\mu_{\mathrm{m}}$ poly(A) sites is attributable to rela- tive 'strengths' of the two poly(A) sites coupled with a variable concentration of a limiting factor that recognizes the sites (Galli et al. 1987, 1988). In each of these cases, the AAUAAA element is invariant. Rather, the differences in the poly(A) sites reside in the downstream sequence element. Thus, an obvious candidate for a regulatory interaction is the CFl interaction that results in stable complex formation. Clearly, if the CF1 factor could interact more tightly with one downstream element than another, such a difference could influence poly(A) site choice. Furthermore, fluctuations in the concentration of the factor might also contribute to the efficiency of poly(A) site utilization.

\section{Experimental procedures}

\section{Extract preparation and fractionation}

HeLa cell nuclear extracts were prepared as described by Dignam et. al. (1983), except that the nuclei were extracted with $350 \mathrm{mM} \mathrm{KCl}$ in the presence of $5 \mathrm{~mm} \mathrm{NaF}, 1 \mathrm{mM} \mathrm{Na}_{3} \mathrm{VO}_{4}$, and $0.1 \mathrm{~mm}$ phenylmethylsulfonyl floride (PMSF). For the fractionation of cleavage factors CF 1 and CF2, a DEAE-Sepharose Fast Flow column (Pharmacia, $2.6 \times 37.7 \mathrm{~cm}$ ) was equilibrated with $75 \mathrm{~mm} \mathrm{KCl}$ in buffer A [ $20 \mathrm{~mm}$ HEPES (pH 7.9), $10 \%$ glycerol, 0.2 mM EDTA, 0.1 mM PMSF, and $0.5 \mathrm{mM}$ DTT]. Nuclear extract ( $200 \mathrm{ml}, \sim 5 \mathrm{mg} / \mathrm{ml})$, dialyzed to $75 \mathrm{mM} \mathrm{KCl}$ in buffer $\mathrm{A}$, was loaded at $200 \mathrm{ml} / \mathrm{hr}$. The column was washed with two volumes of $75 \mathrm{mM} \mathrm{KCl}$ in buffer A and eluted with steps of 150 $\mathrm{mM}$ and $250 \mathrm{mM} \mathrm{KCl}$. For the fractionation of factor PFl, the DEAE column was loaded and washed with $150 \mathrm{mM} \mathrm{KCl}$ in buffer $\mathrm{A}$ and eluted with a $250 \mathrm{mM} \mathrm{KCl}$ step. In each case the peak protein fractions were pooled, dialyzed, and stored at $-85^{\circ} \mathrm{C}$. The DE 150 fractions were dialyzed to $50 \mathrm{mM} \mathrm{KCl}$ and the DE250 fractions to $100 \mathrm{mM} \mathrm{KCl}$ in buffer $\mathrm{A}$.

The following columns were run, as illustrated in Figure 1, for the purification of PF1. An S-Sepharose column (Pharmacia, $2.6 \times 11.3 \mathrm{~cm}$ ) was loaded with $280 \mathrm{mg}$ of the DE150 fraction. The $350 \mathrm{mM}$ step fraction was dialyzed to $20 \mathrm{mM} \mathrm{KCl}$ in buffer B [50 mM Tris $\{\mathrm{pH} 7.8\}, 10 \%$ glycerol, $0.2 \mathrm{~mm}$ EDTA, $0.1 \mathrm{~mm}$ PMSF, and 0.5 mM DTT] and applied to a Mono Q HR10/10 column. The active fractions were dialyzed to $100 \mathrm{mM} \mathrm{KCl}$ in buffer $\mathrm{A}$ and loaded onto a heparin-Sepharose column (Pharmacia, $1 \times 12.7 \mathrm{~cm})$. The active fractions were then applied to a phosphocellulose column (Whatman P11, $1 \times 12.7 \mathrm{~cm}$ ) in 100 mM KCl. PF1 activity was then applied to a Mono S HR5/5 column in $50 \mathrm{mM} \mathrm{KCl}$ in buffer $\mathrm{A}$, and the active fractions were loaded on DNA-cellulose (Pharmacia, $1 \times 12.7 \mathrm{~cm}$ ). A 400- $\mu$ l aliquot of the peak fraction was applied to a $12.5-\mathrm{ml} 10-30 \%$ glycerol gradient containing $100 \mathrm{mM} \mathrm{KCl}$ in buffer $\mathrm{A}$ and centrifuged for $38 \mathrm{hr}$ at $4^{\circ} \mathrm{C}$ at $39 \mathrm{~K}$ in an SW 40 rotor. The molecular weight marker proteins catalase, aldolase, bovine serum albumin, ovalbumin, and chymotrypsinogen A were run in a parallel gradient and subsequently localized by SDS-PAGE.

The DE250 fraction (240 mg) was applied to a Mono S HR $10 / 10$ column in $100 \mathrm{~mm} \mathrm{KCl}$ in buffer $A$ for the purification of PF2 (see Fig. 1). The $500 \mathrm{~mm}$ step fraction was dialyzed to 100 $\mathrm{mM} \mathrm{KCl}$ in buffer $\mathrm{A}$ and loaded on a heparin-Sepharose column (Pharmacia, $1.6 \times 10 \mathrm{~cm}$ ). The active fractions were dialyzed to $100 \mathrm{~mm} \mathrm{KCl}$ in buffer A and loaded on a Blue-Sepharose column (Pharmacia, $1 \times 12.7 \mathrm{~cm}$ ). PF2 activity was then applied to spermine-agarose (Sigma, $1 \times 12.7 \mathrm{~cm}$ ) in $100 \mathrm{mM} \mathrm{KCl}$ in buffer A. PF2 was then loaded on a Mono Q HR 5/5 column in buffer B containing $100 \mathrm{~mm} \mathrm{KCl}$. A $400-\mu$ l aliquot of the peak 
fraction was applied to a $12.5-\mathrm{m} 115-40 \%$ glycerol gradient and centrifuged for $38 \mathrm{hr}$ at $39,000 \mathrm{rpm}$ in an SW40 rotor. The molecular weight marker proteins ferritin, catalase, aldolase, bovine serum albumin, ovalbumin, and chymotrypsinogen $\mathrm{A}$ were run in a parallel gradient and subsequently localized by SDS-PAGE.

For the fractionation of CF1 and CF2, the DE150 fraction 240 $\mathrm{mg}$ ) was applied to a Mono S HR10/10 column in buffer A containing $50 \mathrm{mM} \mathrm{KCl}$ and step-eluted, as shown in Figure 5 . The flowthrough fraction was dialyzed to $50 \mathrm{mM} \mathrm{KCl}$ in buffer $\mathrm{B}$ and applied to a Mono Q HR10/10 column. The CF1 activity was then loaded on a Mono S HR5/5 column in buffer A containing $20 \mathrm{~mm} \mathrm{KCl}$. A $200 \mu \mathrm{l}$ aliquot of the peak fraction was applied to a $5-30 \%$ glycerol gradient containing $100 \mathrm{~mm} \mathrm{KCl}$ in buffer $\mathrm{A}$ and centrifuged for $18 \mathrm{hr}$ at $4^{\circ} \mathrm{C}$ at $50 \mathrm{~K}$ in an $S W 60$ rotor.

\section{Preparation of RNA substrates}

SP6 RNA synthesis was performed as described previously (Gilmartin et al. 1988). The plasmids used for the synthesis of the wild-type (pAAU) and mutant (pAAC) precursors that terminate at the poly(A) site (precleaved RNAs) are described by McDevitt et al. (1988). These plasmids were used for the construction of a second set of SP6 templates in which oligonucleotides were inserted at the AccI site to reconstruct the L3 poly(A) site downstream sequence (for the synthesis of RNAs $\mathrm{AAU}+\mathrm{ds}$ and $\mathrm{AAC}+\mathrm{ds}$ ) or to insert a set of 40 adenylate residues [for synthesis of RNAs AAU $+(\mathrm{A})_{40}$ and $\left.\mathrm{AAC}+(\mathrm{A})_{40}\right]$. The plasmid pAAU + GEM was constructed by the insertion of an EcoRI-PvuII fragment from pGEM2 into an EcoRI-PvuII cut pAAU. The pAAU + GEM plasmid was linearized with HindII for SP6 RNA synthesis to generate an RNA transcript in which the sequence immediately $3^{\prime}$ to the poly(A) cleavage site was replaced by 36 nucleotides of pGEM2 sequence. RNA transcripts were gel purified prior to incubation in the processing reaction.

\section{In vitro $3^{\prime}$-processing assays}

The $3^{\prime}$-cleavage reactions were performed as described previously (Gilmartin et al. 1988), except that reactions using fractionated components were incubated in the absence of $\mathrm{Mg}^{2+}$ and in the presence of $20 \mu \mathrm{g} / \mathrm{ml}$ Escherichia coli tRNA and 1 mM ATP. Specific polyadenylation reactions were performed as described by McDevitt et al. (1988), except for the use of 20 $\mu \mathrm{g} / \mathrm{ml}$ E. coli tRNA. Nonspecific polyadenylation was assayed by replacing $\mathrm{Mg}^{2+}$ with $\mathrm{Mn}^{2+}$.

\section{Complex formation}

Complex formation reactions were performed in a total volume of $25 \mu \mathrm{l}$ containing $1 \%$ polyvinyl alcohol, $20 \mu \mathrm{g} / \mathrm{ml}$ tRNA, 0.7 mM $\mathrm{MgCl}_{2}, 1 \mathrm{mM}$ ATP $5 \times 10^{4}$ Cerenkov cpm of ${ }^{32} \mathrm{P}$-labeled RNA substrate $(0.5 \mathrm{~nm}$ final concentration), and $18 \mu \mathrm{l}$ of processing fraction. Following incubation for $5 \mathrm{~min}$ at $30^{\circ} \mathrm{C}$, heparin was added to $5 \mathrm{mg} / \mathrm{ml}$ on ice. The reactions were incubated further on ice for $10 \mathrm{~min}$ and loaded directly on a $4 \%$ polyacrylamide gel [acrylamide/bis-acrylamide $=80: 1$, in $25 \mathrm{~mm}$ Tris base, $25 \mathrm{~mm}$ boric acid, and $1 \mathrm{~mm}$ EDTA (pH 8)]. Competition experiments were performed by incubation of the processing reaction at $30^{\circ} \mathrm{C}$ for $5 \mathrm{~min}$, as described above, followed by the addition of a 50-fold molar excess of cold substrate RNA. The reaction was continued for an additional $10 \mathrm{~min}$ at $30^{\circ} \mathrm{C}$, and processed as described above.

\section{UV cross-linking}

UV cross-linking reactions were performed in a total volume of $20 \mu \mathrm{l}$ containing $20 \mu \mathrm{g} / \mathrm{ml}$ tRNA, $0.7 \mathrm{mM} \mathrm{MgCl}_{2}, 1 \mathrm{~mm}$ ATP $1 \times 10^{5}$ Cerenkov cpm of $[\alpha-32 \mathrm{P}]$ GTP-labeled RNA substrate and $17 \mu \mathrm{l}$ of processing fraction. After incubation for $5^{\prime}$ at $30^{\circ} \mathrm{C}$, the reactions were irradiated with $254-\mathrm{nm}$ wavelength light (Ultraviolet Light Products model UVG-54) at a distance of 5 $\mathrm{cm}$ for $10 \mathrm{~min}$ on ice. Then, RNase A was added to $50 \mu \mathrm{g} / \mathrm{ml}$, and the reaction was incubated for $15 \mathrm{~min}$ at $37^{\circ} \mathrm{C}$. Protein gel loading buffer was added, and the samples were heated to $100^{\circ} \mathrm{C}$ for $3 \mathrm{~min}$ and electrophoresed on a $10 \%$ SDS-polyacrylamide gel.

\section{Acknowledgments}

We thank Lynne Dengler for her excellent assistance in the preparation of nuclear extracts. This work was supported by a grant from the National Institutes of Health (GM35894).

\section{References}

Birnstiel, M.L., M. Busslinger, and K. Strub. 1985. Transcription termination and $3^{\prime}$ processing: The end is in site! Cell 41: 349-359.

Christofori, G. and W. Keller. 1988. Cleavage and polyadenylation of mRNA precursors in vitro requires a poly(A) polymerase, a cleavage factor, and a snRNP. Cell 54: 875-889.

. 1989. Poly(A) polymerase purified from HeLa cell nuclear extract is required for both cleavage and polyadenylation of pre-mRNA in vitro. Mol. Cell. Biol. 9: 193-203.

Conway, L. and M. Wickens. 1985. A sequence downstream of AAUAAA is required for formation of simian virus 40 late mRNA 3' termini in frog oocytes. Proc. Natl. Acad. Sci. 82: 3949-3953.

- 1987. Analysis of mRNA 3' end formation by modification interference: The only modifications which prevent processing lie in AAUAAA and the poly(A) site. EMBO J. 6: $4177-4184$.

Dignam, J.D., R.M. Lebovitz, and R.G. Roeder. 1983. Accurate transcription initiation by RNA polymerase II in a soluble extract from isolated mammalian nuclei. Nucleic Acids Res. 11: $1475-1489$.

Fitzgerald, M. and T. Shenk. 1981. The sequence of 5'AAUAAA- $3^{\prime}$ forms part of the recognition site for polyadenylation of late SV40 mRNAs. Cell 24: 251-260.

Galli, G., J.W. Guise, M.A. McDevitt, P.W. Tucker, and J.R. Nevins. 1987. Relative position and strengths of poly(A) sites as well as transcription termination are critical to membrane versus secreted $\mu$-chain expression during B-cell development. Genes Dev. 1: 471-481.

Galli, G., J. Guise, P.W. Tucker, and J.R. Nevins. 1988. Poly(A) site choice rather than splice choice governs the regulated production of IgM heavy-chain RNAs. Proc. Natl. Acad. Sci. 85: 2439-2443.

Gil, A. and N.J. Proudfoot. 1984. A sequence downstream of AAUAAA is required for rabbit $\beta$-globin 3 ' end formation. Nature 312: 473-474.

- 1987. Position dependent sequence elements downstream of AAUAAA are required for efficient rabbit $\beta$-globin mRNA 3' end formation. Cell 49: 399-406.

Gilmartin, G.M., M.A. McDevitt, and J.R. Nevins. 1988. Multiple factors are required for specific RNA cleavage to generate a poly(A) addition site. Genes Dev. 2: 578-587.

Guise, J.W., G. Galli, J.R. Nevins, and P.W. Tucker. 1989. Developmental regulation of secreted and membrane forms of 
immunoglobulin $\mu$-chain. In Immunoglobulin genes (ed. $\mathrm{T}$. Honjo, F.W. Alt, and T.H. Rabbitts), pp. . Academic Press, San Diego.

Hart, R.P., M.A. McDevitt, and J.R. Nevins. 1985. Poly(A) site cleavage in a HeLa nuclear extract is dependent on downstream sequences. Cell 43: 677-683.

Hashimoto, C. and J.A. Steitz. 1986. A small nuclear ribonucleoprotein associates with the AAUAAA polyadenylation signal in vitro. Cell 45: 581-591.

Humphrey, T., G. Christofori, V. Lucijanic, and W. Keller. 1987. Cleavage and polyadenylation of messenger RNA precursors in vitro occurs within large and specific $3^{\prime}$ processing complexes. EMBO I. 6: 4159-4168.

Humphrey, T. and N.J. Proudfoot. 1988. A beginning to the biochemistry of polyadenylation. Trends Genetics 4: 243-245.

Kornberg, A. 1980. DNA replication. W.H. Freeman, San Francisco.

Lanoix, J. and N.H. Acheson. 1988. A rabbit $\beta$-globin polyadenylation signal directs efficient termination of transcription of polyomavirus DNA. EMBO J. 7: 2515-2522.

McDevitt, M.A., R.P. Hart, W.W. Wong, and J.R. Nevins. 1986. Sequences capable of restoring poly $(A)$ site function define two distinct downstream elements. EMBO I. 5: 2907-2913.

McDevitt, M.A., G.M. Gilmartin, W.H. Reeves, and J.R. Nevins. 1988. Multiple factors are required for poly(A) addition to a mRNA 3' end. Genes Dev. 2: 588-597.

McLauchlan, J.D., D. Gaffney, J.L. Whitton, and J.B. Clements. 1985. The consensus sequence YGTGTTYY located downstream from the AATAAA signal is required for efficient formation of mRNA $3^{\prime}$ termini. Nucleic Acids. Res. 13: $1347-1368$.

Montell, C., E.F. Fisher, M.H. Caruthers, and A.J. Berk. 1983. Inhibition of RNA cleavage but not polyadenylation by a point mutation in mRNA 3 ' consensus sequence AAUAAA. Nature 305: 600-605

Moore, C.L. and P.A. Sharp. 1985. Accurate cleavage and polyadenylation of exogenous RNA substrate. Cell 41: 845-855.

Moore, C.L., H. Skolnik-David, and P.A. Sharp. 1986. Analysis of RNA cleavage at the adenovirus $2 \mathrm{~L} 3$ polyadenylation site. EMBO J. 5: 1929-1938.

Moore, C.L., J. Chen, and J. Whoriskey. 1988. Two proteins crosslinked to RNA containing the adenovinus L3 poly(A) site require the AAUAAA sequence for binding. $E M B O F$. 7: $3159-3169$.

Nevins, J.R. 1983. The pathway of eukaryotic mRNA formation. Annu. Rev. Biochem. 52: 441-466.

Proudfoot, N.J. and G.G. Brownlee. 1976. The $3^{\prime}$ non-coding region sequence in eukaryotic messenger RNA. Nature 263: $211-214$.

Sadofsky, M. and J.C. Alwine. 1984. Sequences on the 3 ' side of hexanucleotide AAUAAA affect efficiency of cleavage at the polyadenylation site. Mol. Cell. Biol. 4: 1460-1468.

Sheets, M.D. and M. Wickens. 1989. Two phases in the addition of a poly(A) tail. Genes Dev. 3: 1401-1412.

Simonsen, C.C. and A.D. Levinson. 1983. An analysis of processing and polyadenylation signals of the hepatitis $B$ virus surface antigen gene by using simian virus 40 -hepatitis B virus chimeric plasmids. Mol. Cell Biol. 3: 2250-2258.

Skolnik-David, H., C.L. Moore, and P. Sharp. 1987. Electrophoretic separation of polyadenylation-specific complexes. Genes Dev. 1: 672-682.

Stefano, J.E. and D.E. Adams. 1988. Assembly of a polyadenylation-specific $25 \mathrm{~S}$ ribonucleoprotein complex in vitro. Mol. Cell. Biol. 8: 2052-2062.

Takagaki, Y., L.C. Ryner, and J.L. Manley. 1988. Separation and characterization of a poly(A) polymerase and a cleavage specificity factor required for pre-mRNA polyadenylation. Cell 52: 731-742.

Wilusz, J. and T. Shenk. 1988. A 64-kD nuclear protein binds to RNA segments that include the AAUAAA polyadenylation motif. Cell 52: 221-228.

Zarkower, D., R. Stephenson, M. Sheets, and M. Wickens. 1986. The AAUAAA sequence is required both for cleavage and for polyadenylation of simian virus 40 pre-mRNA in vitro. Mol. Cell. Biol. 6: 2317-2323.

Zarkower, D, and M. Wickens. 1987a. Formation of mRNA $3^{\prime}$ termini: Stability and dissociation of a complex involving the AAUAAA sequence. EMBO $/$. 6: 177-186.

- $1987 \mathrm{~b}$. Specific pre-cleavage and post-cleavage complexes involved in the formation of SV40 late mRNA $3^{\prime}$ termini in vitro. EMBO I. 6: 4185-4192. 


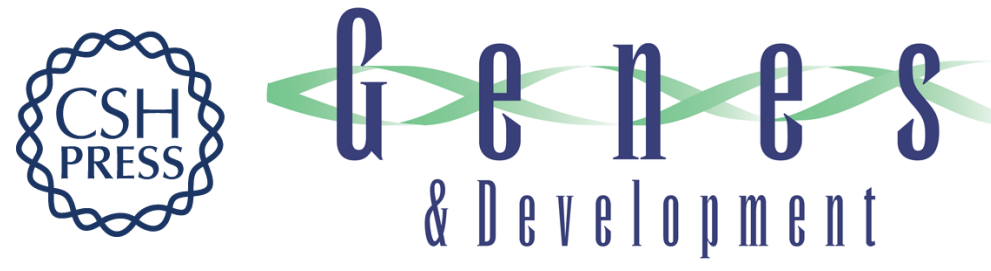

\section{An ordered pathway of assembly of components required for polyadenylation site recognition and processing.}

G M Gilmartin and J R Nevins

\section{Genes Dev. 1989, 3:}

Access the most recent version at doi:10.1101/gad.3.12b.2180

References This article cites 36 articles, 12 of which can be accessed free at:

http://genesdev.cshlp.org/content/3/12b/2180.full.html\#ref-list-1

License

Email Alerting

Service

Receive free email alerts when new articles cite this article - sign up in the box at the top right corner of the article or click here.

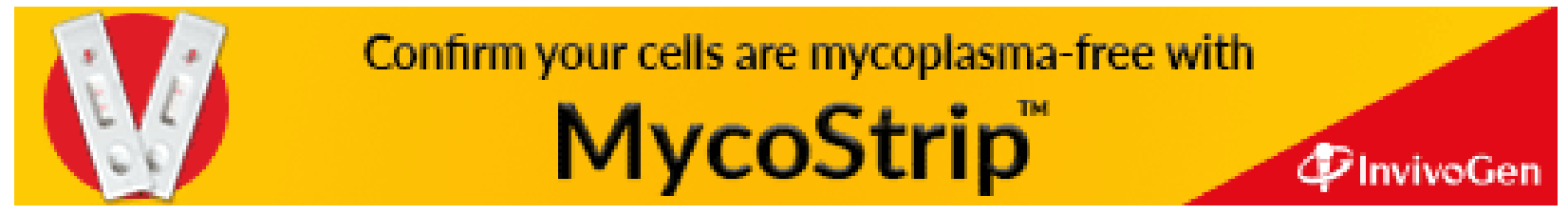

